\title{
Using incoming data to monitor engagement and inform mathematics support interventions
}

Ioannis Lignos, Centre for Student Success, University of East London, United Kingdom.

Email: Lignos@uel.ac.uk

\begin{abstract}
Students who do not engage enough with their studies could place themselves at risk of underperforming or failing. Such a risk may be higher for students who are assessed in one or more mathematics modules and lack the appropriate background knowledge, or do not engage enough with related teaching activities. It has been shown for students who engage with mathematics support, there is a significant impact on student performance and progression in the relevant modules. Thus, improving the mechanisms of engagement with mathematics support should be a priority for any student success strategy.

We discuss the monitoring of attendance and performance data of first-year engineering students, as it becomes available, in order to inform interventions which suit the observed student behaviour best. Specifically, the method described was used with first-year engineering students at the University of East London (UEL) during the 2017-8 academic year. We find that when monitoring processes are applied to an already tailored support package, they can often help maintain engagement levels, understand why some students do not engage, and prompt us to differentiate support further.
\end{abstract}

Keywords: student engagement; data-driven interventions; mathematics support; retention

\section{Introduction}

One of the most widely discussed issues in Higher Education (HE) is student engagement (Vuori, 2014). Research suggests that student engagement has a causal relationship with student academic performance (Fuller et al., 2011). Student engagement refers to attendance and participation in learning and teaching activities, such as lectures, use of online resources, and academic support sessions. In this article, engagement concerns attendance in mathematics support sessions of any type, from one-to-one appointments and drop-in sessions to small group tutorials and workshops. Although the levels of participation between the attendees may differ, when students attend optional activities, they demonstrate a certain level of active attitude towards their studies, and thus we consider mathematics support attendance as a form of student engagement.

Engagement with mathematics support sessions is increasingly important, given that many undergraduate students nowadays lack the appropriate level of mathematical background in relation to their subject (Pell and Croft, 2008). This often makes mathematics support a positive contribution to student progression and retention (Berry et al., 2015) and academic performance (Mac an Bhaird et al., 2009; Jacob and Ní Fhloinn, 2018). Students who engage with mathematics support tend to do better than those who do not, especially in subjects which include mathematics summative assessments, such as engineering (Lee et al., 2008; Rylands and Shearman, 2018). 
A variety of reasons affects engagement with mathematics support. Students being aware of the service and deciding to invest their time are additional challenges for optional teaching activities. Social and emotional reasons and different motivations towards study also affect engagement with mathematics support (Symonds et al., 2008; Mac an Bhaird et al., 2013; Grehan et al., 2016). Another difficulty drawn from our experience is that most students would not commute to the campus to exclusively attend co-curricular activities or use the facilities, unless combined with their academic timetable. This poses an additional challenge in finding appropriate times to offer support sessions.

In this paper, we explore how engagement with mathematics support could be maintained and even enhanced by monitoring the attendance and performance of a cohort of first-year engineering students at UEL in the academic year 2017-8. We are able to identify students who are predicted to be at risk of failing more accurately. Based on emerging trends, we pace and tailor our communications to the cohort and differentiate our support offer to match the circumstances of students who are predicted to struggle with the mathematics module but do not seek for mathematics support.

\section{Mathematics Support for First-Year Engineering Students}

Mathematics support at UEL is provided by the mathematics tutors of the Centre for Student Success, a student service which offers career coaching, employability and academic tutoring services. The mathematics tutors provide workshops, drop-in sessions and one-to-one appointments across two campuses. When appropriate, part of the provision is a diagnostic test tailored to the academic requirements of the course and often a post-diagnostic workshop, where the results of the test and associated feedback is provided to the students.

The first-year engineering students at UEL are required to pass a credit-bearing engineering mathematics module. In this paper, the cohort under study is comprised of two of the possible programme routes available at UEL. The mathematics component of the module for the specific cohort is taught in compulsory lectures and seminars. During both terms of the academic year (twenty-four weeks), the students attend a mathematics lecture every two weeks, and the associated seminar on the week following the lecture. In 2017-8, the module summative assessments included three mathematics written exams in Weeks 9, 21, and 24. Since 2016 the course leaders have opted in for timetabled, but optional, mathematics support workshops, in addition to the types of mathematics support available by default, such as drop-in sessions and one-to-one appointments.

In 2017-8, the support for this cohort was provided by one mathematics tutor, the author of this paper. A diagnostic test took place during the (compulsory) seminar in Week 2, in order to maximise participation. The questions test prior knowledge of the student at that point in time and without preparation, covering the basics of a broad range of topics of foundation mathematics (for engineers). A series of ten optional timetabled workshops was offered in all even weeks from Week 4 to 20, and one in Week 3, planned with the helpful insight of the academic leaders of the cohort. The workshops appear on the online timetable of every student in the cohort, regardless of how the student performed in the diagnostic test.

In the first workshop (post-diagnostic), the answers and techniques seen in the diagnostic test are discussed. An expected outcome of the diagnostic test and the post-diagnostic workshop is that students have identified gaps in their knowledge and understood the importance of engaging with mathematics support. For the rest of the workshops, the tutor sets the topic to be relevant to the previous lectures, reinforcing relevant skills and highlighting key aspects of the lecture material, but the students present have a say on how the workshop evolves. 
Students are encouraged to utilise the rest of the support package, such as drop-in sessions, and individual appointments when they need additional help. Drop-in sessions and individual appointments are the same in structure, where one or more students bring a question to discuss with the tutor at a designated library space. Their difference is that drop-ins run regularly at specific times and days of the week without prior booking, while appointments are bookable and allow for more tutoring time (at least 30 minutes).

\subsection{Addressing lack of awareness and availability of the service}

It is important to demonstrate how we setup mathematics support such that two important practical reasons for non-engagement are contained as much as possible: lack of awareness of the service (Symonds et al., 2008; Patel and Rossiter, 2009), and support being offered at times not suitable for some students (Mac an Bhaird, 2013).

To raise awareness about our service we visit the students in one of their first lectures, and follow other common marketing methods, such as putting up posters at popular points on campus and sending university-wide emails about our service. In these communications, there is a clear, positive message that mathematics support is for every student, improves understanding and performance, and that friendly and patient tutors are happy to address any question. For the specific cohort of firstyear engineering students, perhaps the most effective publicity was that the optional support workshops are timetabled, and thus equally visible to normal lectures and seminars. In addition, a dedicated section on the module VLE page describes the different types of support available.

We also make every effort that our scheduled times for any type of mathematics support are reasonably suitable. Our experience has shown that offering optional timetabled workshops on days when there is no other compulsory lecture or seminar, does not work for most of the students. Besides, that would not have been inclusive towards students who wish to attend but have other commitments allocated for that time. Thus, we look carefully at the student timetable and schedule the workshops on days students must attend other lectures or seminars. Since the cohort schedule in those days is busy, we identify the day with the longest possible break for each of the existing (seminar) groups of the cohort. We timetable more than one iteration of the same workshop such that every seminar group has at least one choice conveniently available. The logic for scheduling drop-in sessions is similar. Since these are open to all students, lunchtime is usually the most appropriate time for most programmes at UEL. In general, we make effort that there is at least one drop-in session which overlaps with one of the (lunch) breaks of every cohort. An easy way to do this is to just extend the duration of the existing drop-in sessions accordingly.

\subsection{Data collection}

We collect data directly from students who use the service, and merge this with student data held centrally from the student registry. We use the data to investigate which students use the service and how they use it, explore what types of support are requested from which courses, and other similar comparisons which can lead to the improvement of the service. After the introduction of the monitoring process, described in the next section, it is required to collate additional performance data related to module assessments, whether formative or summative assessment (SA), or informal assessment based on interactions with the mathematics tutor.

The data available centrally includes student number, name, programme, and route. Diagnostic testing and SA grades are collected as soon as they become available from the faculty. Furthermore, we gather systematically mathematics support data for every student who attends a support session of any type. This data consists of: student number, type of session, date and main topic of the session. We also note other relevant information or points discussed. For some cohorts, this may 
include the level of independence of the student, which the tutor evaluates using a three-point rating scale. More details on this type of evaluation are found in the next section, as it was implemented for the engineering cohort.

\section{Monitoring Engagement}

Monitoring student attendance (or participation) and performance happens unavoidably as part of teaching, for example via assessment and feedback processes. Thus, systematising the monitoring of student engagement with the intention to carry out interventions to increase it, builds on common existing practices in teaching and learning. At the same time, classifying and predicting student behaviour at a detailed level is something which may only be possible using advanced techniques, something which the learning analytics community works on (McKie, 2018).

Perhaps the work most related to a rigorous approach to monitoring engagement involving a mathematics support service is that of Burke et al. (2013). The authors describe the delivery of weekly tutorials to first-year students who are assessed in a mathematics module but not studying towards a mathematics degree. The students were given a set of exercises to work on in groups, asking tutors for advice. They submitted work done in relation to the tutorial, receiving a mark which contributed to the overall module grade. In addition to that, the authors had a dedicated person to monitor who is attending and submitting work. Students who did not engage to a satisfactory level were contacted via email in a multi-stage process, where every emailing round was more urgent in tone, signed by an academic of the department in a respective senior role. The authors report a significant impact of the intervention on the number of students submitting their work and grades.

Although the purpose of the monitoring process we carry out is similar, our process differs in scope and staff perspective. Like Burke et al. (2013), we intervene to engage students who will benefit from attending workshops or other types of support, but our monitoring process does not focus on a specific teaching activity. It tracks the overall engagement of the student with the support service, as an indicator of whether they have addressed their gaps in knowledge. Moreover, the mathematics support tutor did not have the authority to assign work as part of module assessment, and consequently the type and tone of communication interventions differs.

A possible outcome of mapping attendance of support sessions against performance could be better targeted interventions, such as adjusting the timing of service reminders when engagement is low, or sending emails to specific groups when they would be most impactful. Finally, particular student circumstances may become known, which can lead to adapting the type of support offered. In the rest of Section 3, we first outline the basic procedures of our monitoring process, and then we show how we applied those during the academic year 2017-8, by describing specific updates of incoming data and how these led to interventions with the intention to maintain or increase engagement.

\subsection{Setting-up the Monitoring Process}

We call support attendance the level of attendance of any type of mathematics support and cohort performance the distribution of students (count) into different performance groups. Each assessment, including the diagnostic test, can generate three performance groups, namely at-risk, not-at-risk, and unknown-risk. If a certain threshold grade is achieved, the student is not-at-risk, otherwise they are at-risk. If the student did not participate in the assessment, and the latter is not summative, then they are placed in the unknown-risk group.

The cohort performance can contain more than the three performance groups mentioned, when the results of two or more assessments are combined. When the first SA is available, we subdivide the performance groups by creating four (two-by-two) performance groups, based both on the diagnostic 
and the SA. Namely, students who remained in the at-risk or not-at-risk group for both the diagnostic and first SA were placed in the twice-at-risk (T-R) group or twice-not-at-risk (T-NR) groups, respectively. Students who moved from at-risk in the diagnostic to not-at-risk in the first SA or vice versa, they were placed to the at-risk-to-not-at-risk ( $R$--NR) or not-at-risk-to-at-risk (NR-R) groups, respectively. The cohort performance is initialised at the start of the year based on the diagnostic test. Although the threshold for the diagnostic test would usually be close to the standard pass grade for any assessment (40\%), its exact value is determined using heuristics based on some practical reason or observation. If a student does not participate in the diagnostic test, they are classified as unknown-risk, but at-risk if they are repeating the module.

For 2017-8, the diagnostic and first SA were the only major benchmarks, since other assessment data was not available during the teaching period. There was no student who scored between $43 \%$ and $50 \%$ in the diagnostic test, although the questions were assigned the same weight allowing for a uniform set of possible grades from 0 to 100 . Thus, we set the threshold at $45 \%$, following the emerged clustering. There was no obvious clustering for the first SA. We set it at $45 \%$, mainly to allow for a small 'buffer' between the actual pass grade (40\%) and the threshold (and for simplicity being equal to the diagnostic test threshold).

We also collect performance data in relation to specific competencies practiced in a session, when possible. For example, is the student able to carry out matrix multiplication? This is done informally through a discussion and observation on a specific competency during any type of a session. The outcome is measured on a simple 3-item scale based on whether the student is able to complete the task independently: 'yes', 'not sure', and 'no'. 'Not sure' means that they needed help in carrying out the steps during the task but show some understanding. This kind of evaluation is not always possible to carry out objectively for every student during a workshop or small group. That is why, we would update the performance status of the student only if it is somewhat clear that what we observed reflects the actual ability of the student at that moment and, for example, has not been based on input from other students. This rule is followed, even if there is a set task with solutions submitted in a systematic way. Since we wish to encourage group work and not to impose exam conditions, it may be the case that most of the solutions on a given task are a result of a collective effort, where knowledgeable students share parts of the solution. Consequently, most of the tutor evaluations are confirmed with an informal discussion with and observation of the student attempting the task on their own.

These evaluations contribute to updating the status of unknown-risk students, or confirm the accuracy of a previous classification. A 'no' evaluation on a competency at a level required by the diagnostic test material (e.g. how to expand brackets is required when solving simultaneous equations), would signal that a student should be in the at-risk group. A 'yes' evaluation on a competency at a level higher or equal than it is required by the diagnostic test material would signal the opposite. (In practice, this means that not knowing lecture material does not necessarily classify a student as at-risk). We shall note that competency-based monitoring of students has also been used by Gallimore and Stewart (2014) in devising 'individualised learning plans' for students.

Thus, for each student there is a record (in the form of a unique row of a spreadsheet) which is updated weekly, capturing both performance and support attendance data, and performance group classification for each assessment.

\subsection{Monitoring Incoming Data and Data-driven Interventions}

We describe how incoming data in 2017-8 informed our decisions on the type of interventions to carry out, for which students and when. All interventions we list here are data-driven, a result of 
monitoring the available data. What makes them different than other interactions with students is not their actual composition, but their evidence-based trigger and scope.

We provide a timeline of incoming data, updates on cohort performance and the resulting interventions, as they happened week by week. Figure 1 and Table 1 aid in following the roughly chronological description. A 2-week period starts on an even week, for example the 2-week period labelled as Week 4 includes Week 5. Figure 1 summarises support attendance of the cohort attending at any 2-week period during the year. Specifically, the 'Any Mathematics Support' series is support attendance of any type of session, 'First Time Engaged' is support attendance by students who have not attended earlier in the year, and 'Workshop' is support attendance at the workshop of that week. We call unique support attendance the support attendance levels of unique students. Table 1 shows the weekly updates of cohort performance and cumulative unique support attendance by performance group. The cohort performance was initially based on the diagnostic test (Week 2), then it was updated based on the results of the online quiz given during the first workshop (Week 3 ). Students who did not take the diagnostic test, and we had no other evaluation of their performance during the first workshop were placed in the unknown-risk group.

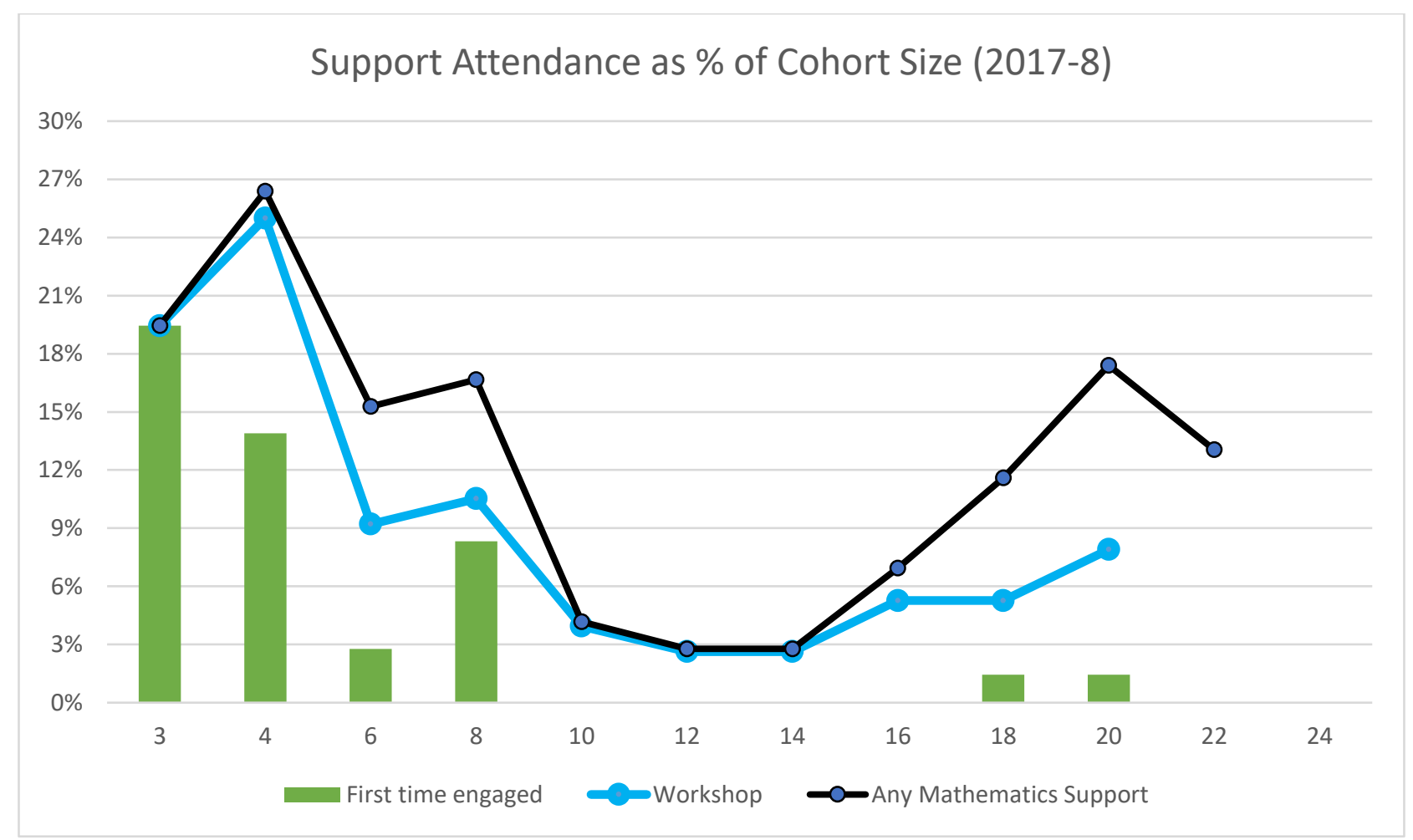

Figure 1. Percentage of the cohort who attended at least once during a 2-week period (starting on the even week) mathematics support, as well as the percentage of unique students engaged for the first time in the year.

Our communication interventions in 2017-8 were messages sent to students' email inbox, either directly from the email account of the author or via the VLE. Of these, standard reminders were sent to the whole cohort, but the trigger to send one could be the existence of a sizeable at-risk group within. However, more targeted emails were sent to specific performance groups, with the content of the message referring to circumstances and facts only applicable to them. For example, we may have referred to their performance or explained why engaging would have been beneficial, including details of tailored support available. Our teaching-related interventions involved the delivery of types 
of support which suited a specific group or the whole cohort at a specific time of the academic year, for example working with small groups.

\section{Cumulative Unique Support Attendance by Performance Group until first SA}

\begin{tabular}{|c|c|c|c|c|}
\hline $\begin{array}{l}\text { Performance } \\
\text { Group }\end{array}$ & at-risk & not-at-risk & $\begin{array}{l}\text { unknown- } \\
\text { risk }\end{array}$ & Cohort \\
\hline $\begin{array}{c}\text { Week } 2 \\
\text { (Diagnostic) }\end{array}$ & 37 students & 23 students & 12 students & 72 students \\
\hline \multicolumn{5}{|c|}{ MS \% (Cumulative) } \\
\hline Week $3^{*}$ & $21 \%(8 / 38)$ & $25 \%(6 / 24)$ & $0 \%(0 / 10)$ & $\overline{14,19 \%}$ \\
\hline Week 4 & $39 \%(15 / 38)$ & $38 \%(9 / 24)$ & $0 \%(0 / 10)$ & $24,33 \%$ \\
\hline Week $5^{\star}$ & $37 \%(15 / 41)$ & $38 \%(9 / 24)$ & $0 \%(0 / 7)$ & $24,33 \%$ \\
\hline Week 6 & $41 \%(17 / 41)$ & $46 \%(11 / 24)$ & $14 \%(1 / 7)$ & $29,40 \%$ \\
\hline $\begin{array}{l}\text { Week } 8 \\
\text { (First SA) }\end{array}$ & $41 \%(17 / 41)$ & $54 \%(14 / 24)$ & $14 \%(1 / 7)$ & $31,43 \%$ \\
\hline First SA & 13 at-risk & 56 not-at-risk & 0 unknown & $\begin{array}{l}69 \text { students } \\
\text { for Term } 2\end{array}$ \\
\hline \multicolumn{5}{|c|}{$\begin{array}{l}\text { *performance groups updated } \\
\text { ^three students withdrawn }\end{array}$} \\
\hline
\end{tabular}

Table 1. Cumulative unique support attendance by performance group is illustrated for every week. Cohort performance was initialised in Week 2 and updated with the first SA results.

In Week 5, one of the students repeating the module informed us that they did not have the same timetable with first-year students. The support workshop, which they had not attended, was the only session on their timetable on the specific day. Three of the repeating students, previously of uknownrisk, were classified as at-risk. A targetted email was sent to these students to attend a group study session, a small group tutorial with time for practice allocated, exclusively arranged for them. Two $(25 \%)$ of these students responded, attending the session, and engaged with us during the year ( 7 visits in total). The reason we arranged their own group study, instead of just signposting to the workshops was both to match their availability but also to prevent them from being affected by reasons for non-engagement associated with at-risk students. In Symonds et al. (2008), 10 out of 17 failing, and non-engaged, students felt intimidation for their lack of knowledge.

By the end of Week 5, engagement of at-risk students was at 37\%. To increase this rate, we sent one message per week to the cohort in Weeks 5 to 7. Two messages were workshop reminders and one a summary of all the types of support available, including the workshops. As a result, two at-risk and five not-at-risk students engaged for the first time, by the end of Week 8, with engaged at-risk students at $41 \%$ of their group.

With the first SA results available, we investigated the performance of non-engaged at-risk students. From the 26 non-engaged at-risk students, 13 students scored at least $60 \%$ in the first SA, and all 
of them below $36 \%$ in the diagnostic. The specific group of 13 students demonstrated on average $302 \%$ improvement on their performance between diagnostic and summative, while the average for all 60 students who took the diagnostic test improved by $149 \%$. Since the size of the at-risk group is a driver for targetted interventions, we decided it was important to revise the cohort performance based on this evidence, deeming the diagnostic result of the 13 students as mispredicting their actual performance group. Thus, 13 students were classified as not-at-risk for both before and after the SA, and so in the T-NR group. This also revised the rate of engaged at-risk students before the SA to $57 \%$.

Table 2 shows unique students' support attendance (at least one visit) for each of the four performance groups, separately for each of the two periods, but also overall in the year. A useful outcome of this view is to see how much different performance groups engaged before but not after the first SA.

\section{Unique Students' Attendance by Performance Group}

\begin{tabular}{|c|c|c|c|c|c|}
\hline $\begin{array}{l}\text { Diagnostic } \\
\text { Test - First } \\
\text { SA }\end{array}$ & $T-R$ & $R-N R$ & $T-N R$ & $N R-R$ & Cohort \\
\hline Up to Week $8^{*}$ & $\begin{array}{c}9 \%(1 / 11) \\
(\operatorname{avg}=3)\end{array}$ & $\begin{array}{l}83 \%(15 / 18) \\
(\operatorname{avg}=1.9,2)\end{array}$ & $\begin{array}{l}37 \%(14 / 38) \\
(\operatorname{avg}=1.5,1)\end{array}$ & $\begin{array}{c}50 \%(1 / 2) \\
(\operatorname{avg}=2)\end{array}$ & $\begin{array}{l}\mathbf{4 5 \%}(31 / 69) \\
(\text { avg }=1.8,1)\end{array}$ \\
\hline After Week 9 & $\begin{array}{c}9 \%(1 / 11)^{\wedge} \\
(\operatorname{avg}=7)\end{array}$ & $\begin{array}{l}39 \%(7 / 18)^{\wedge} \\
(\operatorname{avg}=5.6,3)\end{array}$ & $\begin{array}{l}13 \%(5 / 38) \\
(\operatorname{avg}=1.4,1)\end{array}$ & $0 \%(0 / 2)$ & $\begin{array}{l}17 \%(12 / 69) \\
(\operatorname{avg}=3.8,3)\end{array}$ \\
\hline All Year & $\begin{array}{c}18 \%(2 / 11) \\
(\operatorname{avg}=5)\end{array}$ & $\begin{array}{l}89 \%(16 / 18) \\
(\operatorname{avg}=4.3,2)\end{array}$ & $\begin{array}{l}37 \%(14 / 38) \\
(\operatorname{avg}=2,1.5)\end{array}$ & $\begin{array}{c}50 \%(1 / 2) \\
(\operatorname{avg}=2)\end{array}$ & $\begin{array}{l}48 \%(33 / 69) \\
(\operatorname{avg}=3.3,2)\end{array}$ \\
\hline \multicolumn{6}{|c|}{$\begin{array}{r}\text { avg }=\text { mean, median visits per engaged student } \\
\wedge \text { one new student engaged } \\
{ }^{*} \text { using end of year data retrospectively }\end{array}$} \\
\hline
\end{tabular}

Table 2. Unique students' engagement by cohort performance group. Each unique student attended at least once in each period separately. The performance groups are based on diagnostic and SA.

The average number of visits per performance group, also shown in Table 2, is what measures how often the engaged students attend. Our goal in maintaining engagement in Term 2 was, practically, that both T-R and R-to-NR students attended regularly, such that they are prepared for the upcoming SAs. Their low diagnostic result had suggested that they may have been potentially at-risk in relation to the upcoming SAs, despite their passing of the first SA. Thus, we sent an email before the first workshop of Term 2 to the whole cohort, referring to the importance of keep attending the support workshops.

One reason for low engagement in Term 2 was the focus on other assessments of the course with mid-term deadlines, happening much earlier than the next mathematics SA of Week 21. We know 
this from discussions we had with the academic leaders. Until Week 17, there was no new engaged student and general attendance was at the lowest in the year (Figure 1). This prompted us to explore whether the workshop format was still appropriate as the only type of tailored support, or rather encourage students to choose the type of their choosing. Thus, we scheduled bookable group study sessions (groups of maximum 5 - 6 students) to run in addition to the timetabled workshop. The slots offered were chosen according to seminar group availability. Another option would have been to promote appointments, which are also bookable at various times during the week, but this would have limited the number of students attending at their preferred time.

This arrangement seems to have had some distinct contribution to engagement. There was a total of 13 visits from 9 unique students to three booked group study sessions, between Weeks 18 and 23. Four of the students had not attended any workshop in Term 2, with two of them engaging for the first time. In informal feedback they provided they mentioned that they preferred small group or individual type of support to workshops.

In Week 20, we emailed at-risk students (T-R and NR-to-R). We explicitly referred to the fact that they did not pass the first SA, and that we had the intention to help them do better in the next SAs, listing all the available types of support. Within hours, two T-R students booked to attend the upcoming group study session, but they did not show up on the day, despite the automatic reminder sent 1 day before the booking with the option to cancel. Nevertheless, the e-mail intervention dis spark an initial motivation to engage. We sent a further email to the whole cohort after the second SA in Week 22, reminding them of the support available during the period before the final SA took place. Overall attendance improved near the two assessments, reaching the highest rate since Week 4.

\subsection{Engagement Summary}

In $2017-8,48 \%$ of the cohort engaged with mathematics support at least once, attending one or more of any type of mathematics support. Of those 33 students, $73 \%$ attended at least one of the first two workshops, and 94\% engaged before the first SA in Week 9. The percentage of the cohort who visited at least two, three and four times was $28 \%, 19 \%$, and $13 \%$ respectively. Students who had been at-risk at some point (R, R-NR, and NR-R) attended more than those who were not-at-risk in any of the terms (T-NR). Of the overall mathematics support attendance in the year, $74 \%$ ( 81 visits) was made by at-risk students. The rates of attendance by each of the three at-risk groups and their average number of visits is seen in Table 2. The highest engagement rate in the year was by R-NR students in Term 1 at $83 \%$. On the other hand, only one of the eleven T-R students engaged with us.

\section{Discussion}

With a monitoring process of support attendance and performance data in place, a concurrent status of the cohort is available in respect to who engages with mathematics support and how often. Informed by this data, we plan reminders, targeted emails, and differentiate the types of support at the most appropriate time, if and when it is needed.

Although everyone should benefit from support and there is always scope to help not-at-risk students to do better, our interventions tend to focus on at-risk students. Students weaker in mathematics may be less likely to seek for support (Mac an Bhaird et al., 2013). At the same time, those who do not seek for support are also less likely to be motivated (Symonds et al., 2008) than other students. This requires support mechanisms and interventions which motivate those students to engage. In relation to this, in 2017-8, from the 29 students at-risk in Term 1, 15 engaged early by attending one of the two first workshops. Three more engaged later in Term 2, with some evidence suggesting that 
this was because of appropriate interventions (reminders and the group study initiative). Nevertheless, there were 9 students who according to our records were at-risk until the second SA and did not engage. Three were of those repeating the module who also did not participate or respond to any intervention targeted at them until the end of the year.

As a result of data-driven interventions there were students engaging in good time before the exams in Term 2. Support attendance increased much before the week of the second SA, with less students "cramming" their revision (or support engagement for that matter) in the last minute, as for example we observed in 2014-5 when only drop-in support and appointments were available for specific cohorts (Millwood and Lignos, 2015). Especially in 2016-7 the tailoring of support was mostly similar to 2017-8 with optional timetabled workshops running during the year, but with no particular targetted interventions towards the exam period. It seems that this has had a different effect in Term 2 engagement. In $2016-7,37.5 \%$ of students (6 out of 16) classified as at-risk in the diagnostic test, attended support in Term 2 only in the week of the SA taking place, while for 2017-8 the rate was zero. That is, students attended a mathematics support session for the needs of Term 2 SAs more proactively in 2017-8.

Moreover, data-driven interventions seem to have been effective in maintaining a minimum number of visits of at-risk students, while contributing less to cumulative unique support attendance. On the other hand, most of the unique support attendance was driven by already effective support provision, such as timetabled workshops. The pattern of the 'First Time Engaged' series in Figure 1 shows that most of the students who were aware of the service and decided to engage did so early enough. The cumulative rate of engaged students reached $33 \%$ after the first two support workshops, with almost no other type of support attended and no data-driven intervention. This suggests that the timetabling of the optional support workshops leading on from the diagnostic test was the main cause. After Week 4, unique support attendance grew to $43 \%$ before the first SA. It is not certain whether our email interventions in Term 1 helped increase unique support attendance (the 10\% added between Weeks 4 and 8 ) or this happened because of a fear of failure in the first SA.

According to Rylands and Shearman (2018), our engagement level of $48 \%$ of the cohort is above what they had reviewed in the literature for other mathematics support services (all were below $35 \%$ ), though smaller than their own rate (58\%). Like us, they attributed their high rate to the fact that the support tutorials they offered were timetabled and that three of them were compulsory. It is evident that, in 2017-8, the workshops set out a firm foundation for engaging students at least once, with data-driven interventions potentially boosting that result and securing engagement of more than one visit.

In conclusion, interventions which signpost to types of support which have already reached a high rate of engagement may not significantly increase that rate. Nonetheless, data-driven interventions can help maintain regular attendance and engage hard to reach students. Some of them may be affected by known reasons for non-engagement such as managing their studies and other commitments, low motivation and emotional reasons related to low performance (Symonds et al., 2008; Grehan et al., 2016).

\section{Conclusions and Future Work}

Using performance and support attendance data allowed us to constantly refine the at-risk status of the student. Knowing the latest levels of engagement and personalised performances, we inform targetted interventions, which can potentially engage new students or maintain the already engaged. We identify and target students who are persistently at-risk throughout the year (T-R) or are not deemed as independent as other students, even when they pass the first SA (R-NR). We did so by 
sending tailored reminders about the support available or by differentiating the types of support to suit student circumstances.

We initiated such data-driven processes as a monitoring tool of checking who engages with our support, so that we can intervene when especially students at-risk do not engage adequately. An additional purpose was to know which group to target with interventions that could possibly increase or regulate engagement, by for example getting at-risk students to revise for an exam earlier. Some insights would not have been possible without analysing the data as it became available, and thus we may not have taken action promptly.

The type of interventions used could have been carried out without a data-driven process in place. For example, a successful communication strategy and the trial of new types of support can be done without detailed knowledge of the cohort, and yet engage new students. Also, the timing and type of interventions could be determined by experience and interaction with students only. The difference with data-driven interventions is that there is extra evidence, often previously unknown, to support the necessity of carrying them out. Certainly, being proactive in motivating as many students as possible at the right time is worth the effort, even if the outcome is saving just one more student likely to fail, as Pell and Croft (2008) conclude.

Further work could be done on how competencies map between diagnostic test and SAs. This may affect how the cohort performance thresholds are defined. Furthermore, it seems that there may be a sizeable group of the cohort (19\% for 2017-8) who do not perform accurately in the diagnostic test. We described a heuristic cohort of identifying those students, specific to the 2017-8. This could be developed into a method which can be applied on any cohort.

Different types of interventions could be added to the ones we have carried out. Calling students for attendance and performance issues is the responsibility of the faculty (or specifically the personal tutor) and other services, such as the specialised retention team. Telephone interventions, organised in coordination with these teams, could include direct referrals to mathematics support. Apart from motivating the student, it would be an additional way of confirming that the student has received our intended message, something we do not know with standard email messaing. Moreover, exploring how academic peer-mentoring schemes can be applied successfully at UEL in relation to the improvement of mathematical skills is another way of reaching out to the non-engaged at-risk students, especially in light of success stories elsewhere (Burke et al., 2012). It would be interesting to see how a peer-mentor could not only engage a student with their studies, inclusive of the mathematics component, but also how they could encourage the mentee in attending mathematics support. Finally, extending the monitoring to all cohorts with assessments in mathematics would be of benefit to a mathematics support service in allocating the usually limited support and intervention resources efficiently.

\section{References}

Berry E., Mac an Bhaird, C. and O'Shea, A., 2015. Investigating the relationships between the usage of Mathematics Learning Support and performance of at-risk students. Teaching Mathematics and Its Applications, 34 (4), pp. 194-204. https://doi.org/10.1093/teamat/hrv005

Burke, G., Mac an Bhaird, C., and O'Shea, A., 2012. Peer mentoring for at-risk students. In P. Rowlett and D. Waller, ed. Proceedings of the CETL-MSOR Conference 2012. University of Sheffield, 12-13 July. Birmingham: The Maths, Stats \& OR Network. pp.9-14. Available at: http://www.sigmanetwork.ac.uk/cetl-msor/archive-of-cetl-msor-conference-proceedings-2006-2012/ 
Burke, G., Mac an Bhaird, C., and O'Shea, A., 2013. The Effect of a Monitoring Scheme on Tutorial Attendance and Assignment Submission. International Journal of Mathematical Education in Science and Technology, 44 (4), pp. 545-553. https://doi.org/10.1080/0020739X.2012.756553

Dzator M. and Dzator J., 2018. The impact of mathematics and statistics support at the Academic Learning Centre, Central Queensland University. Teaching Mathematics and Its Applcations. Available at: https://doi.org/10.1093/teamat/hry016

Fuller, M., Wilson, M., and Tobin R., 2011. The national survey of student engagement as a predictor of undergraduate GPA: a cross-sectional and longitudinal examination. Assessment \& Evaluation in Higher Education, 36 (6), pp. 735-748.

https://doi.org/10.1080/02602938.2010.488791

Gallimore M. and Stewart, J., 2014. Increasing the impact of mathematics support on aiding student transition in higher education. Teaching Mathematics and Its Applications, 33 (2), pp. 98-109. https:// doi.org/10.1093/teamat/hru008

Grehan, M., Mac an Bhaird, C. and O'Shea, A., 2016. Investigating students' levels of engagement with mathematics: critical events, motivations, and influences on behaviour. International Journal of Mathematical Education in Science and Technology, 47 (1), pp. 1-28. https://doi.org/10.1080/ $\underline{0020739 X .2015 .1050706}$

Jacob M. and Ni Fhloinn, E., 2018. A quantitative, longitudinal analysis of the impact of mathematics support in an Irish University. Teaching Mathematics and Its Applcations. Available at: https://doi.org/10.1093/teamat/hry012

Lee S., Harrison M.C., Pell, G. and Robinson, C.L., 2008. Predicting performance of first year engineering students and the importance of assessment tools therein. Engineering Education, 3(1), pp. 44-51. https://doi.org/10.11120/ened.2008.03010044

Mac an Bhaird, C., Morgan, T. and O'Shea, A., 2009. The impact of the mathematics support centre on the grades of first year students at the National University of Ireland Maynooth. Teaching Mathematics and Its Applcations, 28 (3), pp. 117-122. https://doi.org/10.1093/teamat/hrp014

Mac an Bhaird, C., Fitzmaurice, M., Ni Fhloin, E., and O'Sullivan, C., 2013. Student non-engagement with mathematics learning supports. Teaching Mathematics and Its Applcations, 32(4), pp.191-205. https://doi.org/10.1093/teamat/hrt018

McKie, A., 2018. UK gets world-first national learning analytics service. [online] Available at: https://www.timeshighereducation.com/news/uk-gets-world-first-national-learning-analytics-service [Accessed 19 November 2018]

Millwood, G. and Lignos, I., 2015. Re-pacing mathematics support to transcend the propensity for "cramming". In: D. Green, ed. CETL-MSOR Conference Proceedings. University of Greenwich, London, 8-9 September. Loughborough University: The sigma Network. pp. 66-73. Available at: http:// www.sigma-network.ac.uk/wp-content/uploads/2016/11/CETL-MSOR-2015-Proceedings.pdf

Patel, R. and Rossiter, A., 2009. Student engagement and non-engagement with maths support. In: D. Green, ed. CETL-MSOR Conference Proceedings. Open University, Milton Keynes, 7-8 September. The Maths, Stats, and OR Network. pp. 99-104. https://www.heacademy.ac.uk/ system/files/proceedings 2009 upload 0.pdf

Pell G. and Croft T., 2008. Mathematics support - support for all? Teaching Mathematics and Its Applcations, 27 (3), pp. 167-173. https://doi.org/10.1093/teamat/hrn015 
Rylands, L.J. and Shearman, D., 2018. Mathematics learning support and engagement in first year engineering. International Journal of Mathematical Education in Science and Technology, 49 (8), pp. 1133-1147. https://doi.org/10.1080/0020739X.2018.1447699

Symonds, R., Lawson, D. and Robinson, C.L., 2008. Promoting student engagement with mathematics support. Teaching Mathematics and Its Applcations, 27 (3), pp. 140-149. https:// doi.org/10.1093/teamat/hrn011

Vuori, J., 2014. Student engagement: buzzword or fuzzword. Journal of Higher Education Policy and Management, 36 (5), pp. 509-519. https://doi.org/10.1080/1360080X.2014.936094 